\title{
A HISTÓRIA DA MATEMÁTICA COMO RECURSO METODOLÓGICO PARA O ENSINO UTILIZANDO O VÍDEO COMO SUPORTE
}

\section{THE HISTORY OF MATHEMATICS AS A METHODOLOGICAL RESOURCE FOR EDUCATION USING THE VIDEO AS SUPPORT}

\author{
Ticiana de Sousa Lima \\ Instituto Federal do Ceará - IFCE \\ Ana Maria Silva Guedes ${ }^{2}$ \\ Universidade Estadual do Ceará - UECE \\ Ana Carolina Costa Pereira ${ }^{3}$ \\ Universidade Estadual do Ceará - UECE
}

\begin{abstract}
Resumo
Com o avanço das Tecnologias da Informação e Comunicação, os recursos audiovisuais têm se tornado um desafio para educadores, no que diz respeito à inserção de vídeos na prática pedagógica. Os vídeos contribuem de forma significativa para o aprendizado do aluno, por serem uma ferramenta que conjuga sons, imagens e ações. Dessa forma, esse artigo traz uma discussão, que alia os vídeos à História da Matemática, a partir das potencialidades que a revisão da literatura realizada coloca e propõe aos professores, isto é, a utilização destes como ferramenta de apoio para o ensino de conteúdos matemáticos. Para isso fez-se um levantamento em artigos, anais, livros, dissertações e teses que discorriam sobre a utilização do vídeo e a História da Matemática. Em seguida, fez-se um estudo descritivo sobre a trajetória do vídeo e vinculou-o com a História da Matemática, no intuito de utilizá-lo como recurso metodológico para o ensino de conteúdos matemáticos. Percebeu-se que autores como Moran (1995), Rocato (2009), Bravo (2000) dentre outros, defendem a partir de um planejamento adequado a inserção do vídeo como ferramenta que possibilita ao educando uma aprendizagem significativa. Além disso, observou-se no trabalho de Machado (2011) a disponibilização de vídeos que permitem aos professores integrarem a História da Matemática com os conteúdos matemáticos. Logo, conclui-se que a História da Matemática aliada ao vídeo oferece ao docente uma opção didática para uma prática pedagógica mais instigante, atrativa e enriquecedora.
\end{abstract}

Palavras-chave: Recursos audiovisuais; Tecnologia da Informação e Comunicação; Educação Matemática.

\section{Abstract}

With the advancement of Information and Communication Technologies, audiovisual resources have become a challenge for educators, regarding the insertion of videos in

\footnotetext{
${ }^{1}$ E-mail: ticianas@yahoo.com.br

${ }^{2}$ E-mail: anamaria_1494@hotmail.com

${ }^{3}$ E-mail: carolina.pereira@uece.br
} 
pedagogical practice. The videos contribute significantly to student learning, as they are a tool that combines sounds, images and actions. Thus, this article brings a discussion, which links videos to the History of Mathematics, based on the potential that the literature review puts and proposes to teachers, that is, the use of these as a support tool for the teaching of mathematical contents. For that, a survey was made of articles, annals, books, dissertations and theses that dealt with the use of video and the History of Mathematics. Then, a descriptive study about the trajectory of the video was made and linked it with the History of Mathematics, in order to use it as a methodological resource for the teaching of mathematical contents. It was noticed that authors like Moran (1995), Rocato (2009), Bravo (2000) among others, defend from a suitable planning the insertion of video as a tool that enables the learner a meaningful learning. In addition, it was observed in the work of Machado (2011) the availability of videos that allow teachers to integrate the History of Mathematics with mathematical content. Therefore, it is concluded that the History of Mathematics combined with video offers the teacher a didactic option for a pedagogical practice that is more exciting, attractive and enriching.

Keywords: Videos; History of Mathematics; Technology of Information and Communication; Mathematics Education.

\section{Introdução}

No decorrer do processo educacional, a educação passou por uma série de transformações, tanto nos aspectos relacionados a utilização dos recursos didáticos presentes no ambiente escolar, quanto nas metodologias utilizadas na aplicação desses recursos.

Frente a isso, o vídeo surge como um recurso alternativo capaz de conduzir a prática docente a melhores resultados no processo de ensino aprendizagem. Embora tenha surgido na educação por volta da década de 70, este ainda é uma ferramenta pouco utilizada no processo educativo. As dificuldades encontradas quanto ao seu uso decorrem: da escassez de investimentos materiais e formação docente (ROCATO, 2009), baixo apoio da gestão escolar (BONICI, 2006), tempo reduzido e resistência por parte dos docentes em adotar esse recurso (BODIÃO, 2000).

Partindo deste contexto, o problema é: qual a importância do vídeo em sala de aula frente as dificuldades levantadas quanto ao seu uso? Para responder a essa pergunta Moran (1995) atribui o planejamento como fator importante dentro desse processo. Além de Moran (1995) outros autores como Belloni (2003), Silva (2011) e Rocato (2009) destacam não só a importância do planejamento, como defendem o uso de vídeos no ensino da matemática. 
Baroni, Teixeira e Nobre (2004) destacam a História da Matemática como recurso metodológico para o ensino. A partir disso, o estudo busca elencar a História da Matemática como recurso metodológico para o ensino, tendo o vídeo como suporte.

Nesse sentido, este estudo baseou-se em pesquisas realizadas por autores que se dedicaram ao tema, no entanto, o diferencial deste refere-se a trazer uma discussão que alia os vídeos à História da Matemática, a partir das potencialidades que a revisão da literatura realizada coloca e propõe aos professores sobre a utilização dos vídeos como ferramenta de apoio para o ensino de conteúdos matemáticos.

\section{Trajetória da inserção do vídeo no processo educativo}

A introdução do vídeo como recurso didático na educação, se deu por volta da década de 60 e 70, através de projetos implementados entre instituições públicas e privadas. As primeiras iniciativas tinham o cunho de ensino a distância e eram transmitidas por meio televisivo.

Por volta da década de 70 surge a necessidade de ampliar a educação com o intuito de reduzir as defasagens de conteúdos e dar oportunidades para alunos que estavam fora da faixa etária escolar.

A partir desse contexto, surgem projetos da Televisão Educativa-TVE com programações de Telensino para serem aplicados na educação pública, voltado para as áreas de formação de professores e cursos "supletivos", ofertados para jovens e adultos que não tiveram chance de concluir os estudos básicos no tempo regular (ROMISZOWSKI, 2004).

No final dos anos 70 e início da década de 80 , surgem os Telecursos de $2^{\circ}$ e $1^{\circ}$ graus, um programa de Educação à Distância - EAD, desenvolvido pela Fundação Roberto Marinho - FRM em parceria com a Fundação Padre Anchieta - FPA, que acreditava na televisão como instrumento para levar educação ao maior número possível de comunidades. Em 1978, a FRM e a FPA criam o Telecurso $2^{\circ}$ grau com objetivo de resolver os problemas educacionais, auxiliar na construção de um país melhor e formar pessoas mais preparadas para enfrentar os desafios advindos da sociedade moderna (EDUCAÇÃO, 2013).

Nesta modalidade de ensino, as aulas eram transmitidas pelo rádio e televisão e voltadas para preparar os adultos para exames de conclusão do Ensino Médio. A transmissão ocorria diariamente por 39 emissoras, incluindo globo e afiliadas e mais nove 
TVs educativas. Devido a isso e às pesquisas realizadas pela Fundação Carlos Chagas, em 1980 o Banco Mundial reconheceu que a iniciativa do Telecurso $2^{\circ}$ grau aumentou o índice de aprovação nos exames supletivos oficiais, além de ter sido a experiência brasileira que preparou mais de 500 mil alunos, sendo motivo de orgulho para Roberto Marinho.

Após o reconhecimento internacional desta produção educativa, em 1981 foi criado o Telecurso $1^{\circ}$ grau. Este programa teve o apoio do MEC e foi direcionado para atender as necessidades educacionais das séries finais do ensino fundamental. As aulas eram ministradas no período de segunda a sexta e reprisadas aos sábados e domingos. Este foi dividido em três fases com duração de 24 semanas cada, em um total de 407 programas, no qual foi transmitido por 14 anos até a criação do Telecurso 2000.

Em paralelo aos programas de Telecurso, a FRM em parceria com o Banco do Brasil e o Fundo das Nações Unidas para a Infância - UNICEF criaram o projeto Vídeo Escola por volta de 1989, que teve o intuito de fortalecer a prática pedagógica dos professores do ensino fundamental e médio dando um suporte para aprendizagem dos estudantes inserindo como complemento do currículo escolar. Com isso, organizaram uma série de filmes de TV e prepararam uma videoteca, que ficou à disposição das escolas (EDUCAÇÃO, 2013).

Este projeto auxiliou na discussão de temas nos quais os alunos apresentavam dificuldades de entendimento e também foi utilizado para reforçar o ensino das escolas públicas. Projeto considerado simples, e a parceria entre professores e alunos ajudou a reduzir os problemas de aprendizagem em diversos conteúdos ministrados na escola.

Em 1995, os programas Telecursos de $2^{\circ}$ e $1^{\circ}$ graus foram substituídos pelo Telecurso 2000. Com isso, foram criadas as salas de aula, em que o professor (orientador da aprendizagem) faz uso da Metodologia Telessala. Estas são equipadas com aparelhos de DVD/vídeo, TV, mapas, livros, dicionários e outros materiais didáticos. Em 2008, este programa passou a ser chamado de Novo Telecurso, onde foram incluídas no currículo do Ensino Médio as disciplinas de Filosofia, Artes Plásticas, Música, Teatro e Sociologia, além de novos cursos profissionalizantes (EDUCAÇÃO, 2000).

Em paralelo como a mudança de nomenclatura do Telecurso, o Ministério da Educação - MEC, em 1996, criou a TV Escola. Esta oferecia aos professores da educação básica, de escolas distantes dos grandes centros urbanos, isoladas e sem acesso aos principais meios de comunicação, uma formação continuada na modalidade à distância 
Ticiana de Sousa Lima, Ana Maria Silva Guedes e Ana Carolina Costa Pereira

A História da Matemática como recurso metodológico para o ensino utilizando o vídeo como suporte

através de um ensino por intermédio de recursos audiovisuais. Neste contexto, capacitou, atualizou e auxiliou professores da rede pública em suas práticas pedagógicas. Além disso, facilitou e disponibilizou conteúdos para educadores, alunos e pessoas interessadas em aprender (BRASIL, 2005).

A plataforma de comunicação utilizada para exibição deste programa é a televisão, e este está disponível em canais abertos, fechados e internet. A transmissão foi realizada via satélite, inicialmente por meio de sinal analógico e depois por sinal digital. A partir do avanço da transmissão e da necessidade de expansão do conhecimento através da tecnologia, surge dentro desta plataforma, o ambiente integrador de conteúdos, na qual disponibiliza através da internet, por meios de websites, smartphone, tablets e smart TV, diversos conteúdos audiovisuais como: dicas pedagógicas de como utilizar os vídeos na sala de aula, fascículos interativos, jogos e outros.

Este programa possui uma videoteca com material sobre diversas áreas temáticas, séries com discussões sobre assuntos diversos, jogos, DVDs, publicações. Possui ainda, o programa Salto para o Futuro, destinado à formação continuada de professores e de gestores da Educação Básica, e uma plataforma de estudo chamada de Hora do Enem, que é um projeto pensado para estudantes que irão fazer o Exame Nacional do Ensino Médio - ENEM. Todos os programas disponíveis na TV Escola, possuem recursos audiovisuais com o propósito de proporcionar tanto para alunos como para professores, conteúdos mais acessíveis, significativos, reflexivos e compreensíveis.

Segundo Belloni (2003), o programa TV Escola inicialmente buscava atender aos professores dos primeiros anos do ensino fundamental, devido serem formados em cursos de magistério, mas após um período, foi ampliado para todos os níveis de professores da educação básica. Contudo, a autora destaca em sua pesquisa que o uso em menor frequência dos vídeos da TV Escola deve-se aos professores formados em curso de magistério, devido à baixa qualidade em sua formação e a falta de preparo na compreensão das propostas de utilização dos materiais disponibilizados pela TV Escola.

Por outro lado, Silva (2011) relata em sua pesquisa o interesse dos professores de mudarem sua prática de ensino com a inserção da tecnologia, tais como: computador, vídeos e televisão. Entretanto, essa mudança torna-se insuficiente devido a precariedade material, estrutural e financeira para planejar, incorporar e avaliar o uso desses recursos na prática docente. 
Mas para a autora, além do desejo de mudança, a ação de planejar com o uso das Tecnologias da Informação e Comunicação - TIC é extremamente importante, pois racionaliza as atividades desenvolvidas por docentes e discentes durante o processo de ensino e aprendizagem, objetivando melhores resultados no que diz respeito ao desenvolvimento do pensamento crítico e reflexivo.

Com o desenvolvimento das TIC, os vídeos educativos passaram por uma evolução. Inicialmente eram produzidos no formato de VHF (Very High Frequency), sendo convertidos para o formado de DVD (Digital Versatile Disc) e hoje, com o advento da internet, passaram a ser disponibilizados na própria rede. Esse processo é confirmado por Rocato (2009, p. 49) ao declarar que: “ com a união das mídias computador, vídeo e internet, amplia o uso de vídeos e abre diversas possibilidades de trabalho dentro do campo educacional na construção do conhecimento".

A internet dispõe de inúmeras informações escritas, audiovisuais e interativas, na qual visualiza-se textos, documentários, músicas, vídeos entre outros, sobre diversos assuntos. Neste contexto, o Portal Domínio Público, criado em 2004, é uma biblioteca virtual que apresenta um papel de destaque: compartilha, incentiva, inova e produz discussões sobre o conhecimento. Sendo esta consultada por docentes, estudantes, pesquisadores e interessados (BRASIL, 200-).

Em 2005 foi criado o YouTube, site muito visualizado e utilizado por milhares de pessoas do mundo. Os usuários carregam e compartilham vídeos em formato digital, tais como: videoaula, séries educativas, documentários, filmes entre outros. Muitos dos recursos presentes podem ser utilizados tanto por professores, quanto por alunos, pois auxilia a compreensão, ampliação, inovação e conhecimento de assuntos diversos.

Em 2008, o MEC junto a outras instituições internacionais desenvolveu um repositório educacional denominado de Banco Internacional de Objetos Educacionais BIOE, com o intuito de aprimorar a inserção das mídias no contexto educacional e propiciar aos professores recursos pedagógicos de qualidade para serem articulados ao plano de aula. Os Objetos Educacionais - OE disponíveis no BIOE são recursos que suplementam o processo de ensino-aprendizagem e possuem diferentes formatos como: simulação, animação, experimentos práticos, vídeos, imagens, hipertextos, softwares educacionais. Diante desta diversidade de materiais, o professor tem a oportunidade de criar diferentes estratégias pedagógicas, a fim de potencializar o processo educativo. 
Uma outra plataforma utilizada na educação é o portal Matemática Multimídia $\mathbf{M}^{3}$. Este foi desenvolvido em 2011 e contém recursos educacionais, multimídias em formatos digitais desenvolvidas pela Universidade Estadual de Campinas - UNICAMP, com financiamento do Fundo Nacional de Desenvolvimento da Educação - FNDE, Secretaria de Educação - SED, Ministério de Ciência e Tecnologia - MCT e Ministério da Educação - MEC destinada aos alunos do Ensino Médio, na área de Matemática. Esta plataforma possui mais de 350 mídias no formato de vídeos, softwares e experimentos, sendo 180 vídeos baseados em diversos conceitos de conteúdos matemáticos. Este projeto foi licenciado pela Creative Commons, no qual permite cópia, distribuição, exibição, execução e criação de obras com acesso livre.

O MEC, em 2016, desenvolveu a plataforma MECFLIX com o objetivo de ajudar os discentes no aprendizado de conteúdos voltados para o ENEM. Nesta são disponibilizadas videoaulas gratuitas, oferecendo ao usuário aproximadamente 1900 vídeos divididos nas áreas de: ciências da natureza e suas tecnologias; ciências humanas e suas tecnologias; linguagens, códigos e suas tecnologias e matemática e suas tecnologias. Esta, por sua vez, é alimentada e avaliada continuamente pelos parceiros do MEC e corresponde a um meio de inserção do recurso audiovisual, auxiliando o processo educativo.

Além dos projetos, plataformas e sites citados anteriormente, que utilizam o vídeo como uma ferramenta, a videoconferência surge como uma alternativa para atender o ensino à distância. Dessa forma, com os avanços tecnológicos, em especial da internet, o ensino nessa modalidade se propaga de modo a proporcionar uma interação entre professores e alunos em tempo real.

Diante deste cenário, foi criado em 2007, o projeto "Ensino Presencial com Mediação Tecnológica”, pelo governo do estado do Amazonas. Este teve como objetivo oferecer educação às comunidades amazonenses de lugares longínquos, através de videoconferência. $\mathrm{O}$ projeto foi implementado inicialmente no ensino fundamental, em seguida no ensino médio. Além destes, atende a Educação de Jovens e Adultos-EJA. A equipe conta com professores especialistas em cada disciplina e um tutor em cada turma, ademais as aulas eram ministradas de estúdios localizados no centro de mídias, em Manaus, e acompanhadas por 3 mil estudantes que interagem ao mesmo tempo.

Observando a trajetória de utilização do vídeo no processo educativo, verificouse que existem diversas plataformas que podem ser inseridas na sala de aula. Estas por 
sua vez são pouco utilizadas, seja por falta de conhecimento da existência sobre alguns conteúdos matemáticos e/ou pelo despreparo do professor para utilização da ferramenta, como destacado pelos autores Belloni (2003), Rocato (2009) e Silva (2011). Tendo em vista que, a inserção do recurso audiovisual no processo educativo necessita de planejamento específico.

Rocato (2009) destaca que a utilização do recurso audiovisual precisa ser acompanhada por um planejamento organizado para se ter um aproveitamento satisfatório da ferramenta. Neste contexto, verifica-se o quão é importante o ato de planejar, pois a falta desse requisito pode proporcionar uma utilização inadequada do recurso, acarretando assim problemas de aprendizagem. $\mathrm{O}$ autor ainda sublima que o recurso por si só não é suficiente para sanar as falhas no processo de aprendizagem.

\section{Uso de vídeos voltados para sala de aula}

Historicamente o ensino da matemática sempre revelou inúmeros desafios para prática docente. Normalmente, com um grau de dificuldade maior do que as demais disciplinas, essa tem sido considerada, pela maioria dos alunos, como a disciplina que gera muitas dúvidas e questionamentos no âmbito escolar (DAMACENO, 2013). É comum encontrarmos pessoas que a apontam como uma matéria de difícil compreensão devido à forma tradicional como normalmente é abordada na sala de aula. Nesse sentido, Souza (2010, p. 2) declara que "as dificuldades encontradas pelos estudantes em relação à matemática geralmente se referem a não compreenderem o que está sendo lhe ensinado ou não saberem como utilizar o que foi "adquirido"”".

São múltiplos os fatores ligados as dificuldades apresentadas na compreensão de conteúdos matemáticos, tais como: falta de tempo para abordagem de todos os conteúdos da grade curricular; recurso didático diminuto; infraestrutura precária; metodologia ultrapassada, alunos desmotivados, deficiências no sistema de ensino e falta de qualificação para os professores, em especial, voltada para utilização dos recursos tecnológicos. Isso acaba dificultando o aprendizado tornando um motivo de preocupação para a educação.

Minimizar esses problemas tem sido motivo de apreensão para o sistema de ensino público, tendo em vista que os índices do Instituto de Desenvolvimento da Educação 
Ticiana de Sousa Lima, Ana Maria Silva Guedes e Ana Carolina Costa Pereira

A História da Matemática como recurso metodológico para o ensino utilizando o vídeo como suporte

Básica-IDEB $^{4}$ que medem o desempenho escolar da rede pública mostram que a disciplina de matemática está muito aquém do necessário. Entretanto, sabemos do importante papel que a matemática desempenha na sociedade, por está intrinsecamente ligada com as demais ciências.

Segundo os Parâmetros Curriculares Nacionais - Ensino Médio-PCNEM (BRASIL, 2000, p. 9)

A Matemática, por sua universalidade de quantificação e expressão, como linguagem, portanto, ocupa uma posição singular. No Ensino Médio, quando nas ciências torna-se essencial uma construção abstrata mais elaborada, os instrumentos matemáticos são especialmente importantes. Mas não é só nesse sentido que a Matemática é fundamental. Possivelmente, não existe nenhuma atividade da vida contemporânea, da música à informática, do comércio à meteorologia, da medicina à cartografia, das engenharias às comunicações, em que a Matemática não compareça de maneira insubstituível para codificar, ordenar, quantificar e interpretar compassos, taxas, dosagens, coordenadas, tensões, frequências e quantas outras variáveis houver.

Percebe-se a importância do estudo matemático e, apesar das dificuldades apresentadas pelos discentes, aos professores resta o desafio de motivar seus alunos para compreenderem o papel desempenhado pela mesma em relação ao desenvolvimento de competências e habilidades necessárias no decorrer do processo educativo, social e profissional.

Além disso, os professores têm que adentrar no mundo tecnológico, buscando alternativas e estratégias modernas para dentro da sala de aula, inserindo recursos na sua prática pedagógica, tendo em vista, que os estudantes estão cada dia mais incorporados nesse mundo.

Dentre os recursos didáticos utilizados no ambiente escolar que desperta $o$ interesse dos estudantes, destaca-se o vídeo. Isso é explicado por Bravo (2000) ao ressaltar as seguintes características: baixo custo, facilidade de uso e acesso por meio digital. Além disso, o autor destaca a utilização desse recurso como forma de inserir o educando em diferentes momentos do processo educativo, tais como a observação, expressão e autoaprendizagem.

\footnotetext{
${ }^{4}$ Portal IDEB. Disponível em: <http://portal.inep.gov.br/web/portal-ideb/portal-ideb>. Acesso em 20 de maio de 2016.
} 
Nessa perspectiva, além de Bravo (2000), outros autores como, Borba e Villarreal (2005) e Moran (1995) também destacam a importância do vídeo enquanto instrumento didático.

Para Borba e Villarreal (2005) o vídeo aplicado no ensino da matemática é um recurso de apoio utilizado na comunicação e produção de ideias e este acomoda o tipo de matemática e o tipo de pensamento desenvolvido pelos participantes do processo de ensino-aprendizagem. Vinculados a esta ideia, os autores destacam que: "o processo de visualização atinge uma nova dimensão se considerar um ambiente computacional de aprendizagem com um coletivo pensante particular, onde estudantes, professores/ pesquisadores, mídia e conteúdos matemáticos residem juntos” (BORBA E VILLARREAL, 2005, p. 96, tradução nossa) $)^{5}$.

Para estes autores, a mídia audiovisual desempenha um papel importante na construção do conhecimento matemático, se utilizado de maneira organizada e racional. Dessa forma, o conhecimento é construído a partir das interações dos seres humanos com as mídias, que reorganizam, moldam e influenciam o pensamento, de modo a provocar mudanças no comportamento.

Moran (1995) destaca o processo de visualização como um ato que auxilia na aprendizagem devido as possibilidades de combinar sons, imagens, escritas, movimentos e múltiplos arranjos. Este por sua vez nos informa, seduz, projeta para outras realidades e chama atenção através da linguagem falada, escrita, imagética, provocando mudanças na forma de pensar.

A partir disso Moran (1995, p. 29) afirma que: “o vídeo combina a comunicação sensorial-cinestésica com a audiovisual, a intuição com a lógica, a emoção com a razão. Combina, mas começa pelo sensorial, pelo emocional e pelo intuitivo, para atingir posteriormente o racional".

Diante dos aspectos apontados, observa-se que o docente precisa determinar estratégias de ensino-aprendizagem com a utilização do recurso audiovisual, que promova um ensino dinâmico, interativo, crítico e reflexivo. De modo a atingir uma aprendizagem com significação.

\footnotetext{
${ }^{5}$ Traduzido pelo autor. The visualization process reaches a new dimension to consider a computer learning environment with a particular collective thinking, where students, teachers / researchers, media and mathematical content reside together.
} 
Ticiana de Sousa Lima, Ana Maria Silva Guedes e Ana Carolina Costa Pereira

A História da Matemática como recurso metodológico para o ensino utilizando o vídeo como suporte

\section{História da Matemática como recurso metodológico para sala de aula utilizando como suporte o vídeo}

A História da Matemática destaca-se no cenário da Educação Matemática no Brasil, por possibilitar a compreensão, a apresentação, o surgimento e o desenvolvimento da matemática ensinada em sala de aula.

O ensino da matemática, às vezes, é uma tarefa muito difícil, devido às dificuldades que os professores encontram em explicar alguns porquês para os alunos, tais como o surgimento das fórmulas, os conceitos e os instrumentos entre outros. Isso é explicado pela História da Matemática, tendo em vista mostrar que a matemática ensinada em sala de aula é fruto de resultados de vivências e necessidades do dia a dia.

De acordo com Baroni, Teixeira e Nobre (apud, 2004, p. 172), "acredita-se que a História da Matemática seja um instrumento que destaca o valor da matemática em sala de aula e mostra aos alunos a amplitude da mesma, fazendo-os perceber que a matemática vai muito além dos cálculos".

Assim, percebe-se a importância da História da Matemática, como um recurso metodológico que contribui para sanar as dificuldades dos alunos em compreender fórmulas, conceitos matemáticos e suas utilizações, além de apresentar interdisciplinaridade dessa disciplina.

Desta forma, para chamar a atenção do aluno para as aulas de matemática, a História vem como um suporte informativo e explicativo, pois leva o aluno desinteressado a gostar da disciplina, potencializar o pensamento crítico e desenvolver a criatividade na resolução de problemas.

Além da História da Matemática, a inserção de vídeos vinculados a esta torna as aulas mais atrativas e proveitosas. Por meio deste pode-se conhecer os fatores sociais, culturais e históricos que acontecem em cada época e com cada povo.

Desse modo, a disciplina de História da Matemática torna-se importante para os professores de matemática, por levar os conhecimentos adquiridos em sua formação para sala de aula, pois permite a transformação da disciplina em metodologia de ensino.

Antigamente era muito preocupante usar um novo recurso em sala de aula, mas com avanço da tecnologia isso torna-se possível devido estar mais próxima da realidade dos estudantes. Inicialmente a implantação de vídeo nas aulas era vista como forma de lazer, mas o recurso causou uma ruptura nos procedimentos educacionais pautados apenas nas linguagens verbal e escrita, levando para sala de aula, som e imagens. 
O vídeo por si só já é um recurso atrativo, pois leva o aluno a uma aula diferente, fugindo das aulas tradicionais, chamando a sua atenção. Ao utilizar o vídeo é muito importante escolher o momento mais adequado para inseri-lo, seja para introduzir, fixar ou finalizar um conteúdo, dessa forma, o docente enriquece a aula, por apresentar o conteúdo de forma simples, resumida e atrativa, tornando as aulas mais proveitosas.

Isso é observado no trabalho de Machado (2011) ao elencar alguns vídeos que relacionam a História da Matemática com conteúdos matemáticos. Dentre estes, destacam-se: vídeos da TV Escola, das séries Mão na forma; Artes e Matemática e Matemática na vida - razão e proporção: conceito do dia a dia e Matemática em toda parte.

A série Mão na forma é composta por sete episódios voltados para conteúdos sobre as formas geométricas, na qual o professor pode utilizar-se desse recurso para auxiliar os estudantes a compreenderem as teorias e regras da geometria, de modo a desvendar as dificuldades apresentadas por estes, tendo em vista tornar o ensino dinâmico, interativo e significativo.

A série Artes e Matemática, trata-se das relações existentes entre as manifestações da arte como: pintura, escultura, arquitetura, música e o raciocínio matemático. Através desta série, o professor pode apresentar aos alunos as relações existentes entre a matemática e a música, os padrões da natureza associados com as formas geométricas, as igualdades, as regularidades, as repetições, a simetria, a proporção das formas dentre outros aspectos.

Outra série em destaque é a Matemática na vida - Razão e Proporção: conceito do dia a dia, a partir desta, o professor pode apresentar e discutir assuntos sobre conceito de proporcionalidade e relacioná-los com situações problemas voltados para o cotidiano dos alunos.

E ainda a série Matemática em toda parte, esta é composta por 12 episódios, no qual o professor pode apresentar aos alunos várias possibilidades de aprender matemática de maneira diferenciada da tradicional. Através de situações problemas aplicados na arte, na construção, na escola, na música, nas finanças, no futebol, no parque, nas feiras, nos mercados e nos sítios, as quais irão despertar a atenção dos alunos proporcionando aulas atrativas, instigantes, dinâmicas e significativas, por fazerem parte dos ambientes e situações vivenciadas no decorrer do dia a dia dos estudantes.

Além dos vídeos da TV Escola, destaca-se ainda a Fábulas Disney- Donald no país da Matemágica, que traz de maneira lúdica conteúdos sobre a regra de ouro, o 
teorema de Pitágoras, a relação entre a matemática e a música dentre outros. Estes podem ser utilizados no ensino fundamental com o intuito de agregar valor significativo, enriquecendo o conhecimento prático e teórico sobre conteúdos voltados para música, arquitetura, esporte, artes e situações advindas do cotidiano dos alunos.

Logo, pode-se observar que a História da Matemática utilizada como recurso metodológico para sala de aula, aliado com o vídeo é uma estratégia enriquecedora para as aulas de matemática, pois estimula cada vez mais os alunos a pesquisarem e se interessarem por matemática.

\section{Considerações Finais}

A utilização de vídeos vinculados com a História da Matemática é uma opção didática que possibilita o melhor aproveitamento do processo de ensino-aprendizagem de matemática por trabalhar de maneira interativa, dinâmica e instigante os conteúdos matemáticos de modo a proporcionar ao educando uma aprendizagem crítica e reflexiva, tornando-o sujeito ativo no processo de ensino.

Os recursos audiovisuais trazem para sala de aula elementos que permitem e facilitam a comunicação entre o professor e o aluno. A linguagem plural dos vídeos aliados com a História da Matemática tem um papel fundamental nesse processo, enquanto os livros e as suas abordagens mais tradicionais do discurso didático em matemática são mais descontextualizados e lineares. A linguagem dos vídeos se aproxima mais das experiências extraescolares dos alunos da geração do computador.

Assim, a partir da inserção de vídeos vinculados com a História da Matemática, o professor desperta no educando o interesse pela disciplina. Como resultado, observa-se uma mudança na forma de pensar e consequentemente no agir.

\section{Referências}

. Ministério da Educação. Portal Domínio Público. Brasília: MEC, 200-.

Disponível em: <http://www.dominiopublico.gov.br/Missao/Missao.jsp>. Acesso em: 15 de maio 2016.

Ministério da Educação. Portal Domínio Público. Brasília: MEC, 2005.

Disponível em: <http://tvescola.mec.gov.br/tve/sobre>. Acesso em: 16 de maio 2016.

Secretaria de Educação Média e Tecnológica. Parâmetros Curriculares Nacionais Ensino Médio. Brasília: MEC /SEMTEC, 2000. 
<http://www.ice.upm.es/wps/jlbr/Documentacion/Libros/Videdu.pdf $>$.Acesso em: 07 fev. 2016.

BARONI, R. L. S.; TEIXEIRA, M. V.; NOBRE, S. R. A Investigação Científica em História da Matemática e suas Relações com o Programa de Pós-Graduação em Educação Matemática. In: BICUDO, M. A. V.; BORBA, M. C. (Orgs.). 62 Educação Matemática: pesquisa em movimento. São Paulo: Cortez, p. 164-185, 2004.

BELLONI, M. L. A televisão como ferramenta pedagógica na formação de professores. Educação e Pesquisa, São Paulo, v. 29, n. 2, p. 287- 301, jul./dez. 2003.

BODIÃO, I. S. O Telensino: que didática é essa?. 23ª Reunião Anual da Associação Nacional de Pós-Graduação e Pesquisa em Educação. Caxambu, Minas Gerais. 2000. Disponível em: <http://www.anped.org.br/sites/default/files/gt_04_02.pdf >. Acesso em: 20 de novembro 2016.

BONICI, R. M. C. Tecnologia de Informação e Comunicação: fatores críticos que facilitam seu uso por professores da rede pública de São Paulo.2006.139f. Dissertação o em Ensino de Ciências e Matemática - Universidade Cruzeiro do Sul, São Paulo, 2006.

BORBA, M. C.; VILLARREAL, M. V. Humans-With-Media and the Reorganization of Mathematical Thinking: information and communication technologies, modeling, experimentation and visualization. New York: Springer, 2005.

BRAVO, J. L. R.; El Vídeo educativo. enero. 2000. Disponível em:

DAMACENO, L. M. A aula de Matemática em vídeo e as Redes Sociais como recursos didáticos: uma experiência com a disciplina Estatística no Ensino Médio Inovador. Dissertação do Mestrado Profissional em Matemática em Rede Nacional PROFMAT da Universidade Estadual do Sudoeste da Bahia, Vitória da Conquista. p.15, 2013.

EDUCAÇÃO, Telecurso $1^{\circ}$ Grau. Rio De Janeiro: Fundação Roberto Marinho, 2013. Disponível em: <http://www.robertomarinho.com.br/obra/fundacao-robertomarinho/educacao/telecurso-1-grau.htm>. Acesso em: 10 de maio 2016.

EDUCAÇÃO, Telecurso $2^{\mathbf{0}}$ Grau. Rio De Janeiro: Fundação Roberto Marinho, 2013. Disponível em: <http://www.robertomarinho.com.br/obra/fundacao-robertomarinho/educacao/telecurso-2-grau.htm>. Acesso em: 10 de maio 2016.

EDUCAÇÃO, Telecurso. Rio De Janeiro: Telecurso, 2000. Disponível em: <http://educacao.globo.com/telecurso/noticia/2014/11/metodologia-telessala.html>. Acesso em: 10 de maio 2016.

EDUCAÇÃO, Vídeo Escola. Rio De Janeiro: Fundação Roberto Marinho, 2013. Disponível em: <http://www.robertomarinho.com.br/obra/fundacao-robertomarinho/educacao/video-escola.htm>. Acesso em: 10 de maio 2016. 
Ticiana de Sousa Lima, Ana Maria Silva Guedes e Ana Carolina Costa Pereira

A História da Matemática como recurso metodológico para o ensino utilizando o vídeo como suporte

MACHADO, B. F. Vídeo-aula de história da matemática: uma possibilidade didática para o ensino de matemática. 2011.144f. Dissertação (Mestrado em Ensino das Ciências e da Matemática) - Universidade Federal do Rio Grande do Norte - UFRN, Natal, 2011.

MORAN, J. M. O vídeo na sala de aula. Comunicação e Educação, São Paulo, v.2, p.28, 1995.

ROCATO, P. S. As concepções dos professores sobre o uso de vídeos como potencializadores do processo de ensino e aprendizagem. 2009. 176f. Dissertação (Mestrado Profissional em Ensino de Ciências e Matemática) - Universidade Cruzeiro do Sul-UNICSUL, São Paulo, 2009.

ROMISZOWSKI, A. Uma visão histórica e pessoal da evolução da Educação à Distância. Revista Brasileira de Aprendizagem Aberta e à Distância. São Paulo, v. 2, n. 4, 2004. Disponível em: <http://www.abed.org.br/publique/cgi>. Acesso em: 13 de maio 2016.

SILVA, A. M. O vídeo como recurso didático no ensino de matemática. Dissertação do Mestrado em Educação em Ciências e Matemática. Universidade Federal de Goiás, Goiás. 2011.

SOUZA, J. F. Trabalhando uma nova prática de ensino para o aprendizado da matemática. Semana Educa, Porto Velho, v. 1, n. 1, 2010. 